\title{
Bioengineering Approaches to Controlled Protein Delivery
}

\author{
SERGE KOBSA AND W. MARK SALTZMAN
}

Department of Biomedical Engineering, Yale University, New Haven, Connecticut 06520

\begin{abstract}
Proteins are of crucial importance in all biologic organisms, in terms of both structure and function. Their deficits play central roles in many pathologic states, and their potential as powerful therapeutic agents has been widely recognized. Many issues, however, exist in delivery of biologically active proteins to target tissues and organs. Recent advances in biomedical engineering have lead to development of advanced techniques for controlled delivery of peptides and proteins, paving the way for their efficient use in treating human injury and disease. With a particular emphasis on most recent advances, this review discusses currently available techniques for controlled delivery of proteins and considers future research directions. (Pediatr Res 63: 513-519, 2008)
\end{abstract}

B ioactive agents are the pillars of therapy for human disease. Throughout much of history, active substances have been prepared and ingested in the form of unpurified natural extracts, guided by little more than anecdotes and intuition. Modern science, however, brought with it an understanding of the principles of biochemistry, molecular biology, and genetics. These advances in basic sciences have elucidated the complex relationships that govern health and disease. Although, conceptually, the most basic approachdelivery of bioactive agents to correct pathologic processeshas remained largely unchanged, today the choices of pharmacologic agents and their targets are guided by scientific evidence. Furthermore, developments in genetic engineering, combinatorial chemistry, and high-throughput pharmacologic screening techniques mean that 21 st century biomedical scientists and clinicians have at their disposal large numbers of novel agents. There is an almost limitless potential for developing new, individualized agents-designed for targets specific to a person - a trend that will likely lead to emergence of personalized medicine.

\section{PROBLEMS EXIST IN DELIVERY OF BIOACTIVE AGENTS}

For an agent to be effective, it must reach its biologic target. This is often a challenging problem in a living organism. Therefore, despite the above mentioned scientific advances, a disparity is still present with respect to the existence of bioactive agents that are effective in vitro, and those of them that produce desired effects in vivo in practical and reproduc-

Received November 9, 2007; accepted November 29, 2007.

Correspondence: W. Mark Saltzman, Ph.D., Department of Biomedical Engineering, Yale University, P.O. Box 208260, 55 Prospect St., MEC 414, New Haven, CT 06520-8260; e-mail: mark.saltzman@yale.edu

The work on protein delivery was supported by the National Institutes of Health (grants EB000487, NS45236, HL085416, and DK077910). ible ways. In other words, agents that work well in cell culture are not always useful in human clinical applications. This problem is partly reflected in the fact that even though research and development investments have increased, the numbers of drugs approved by the FDA for human use have remained largely the same (1).

There are several principal reasons why an agent that is biologically effective in vitro may prove to be ineffective and impractical for human clinical use (2). Some of these failures arise from the biologic differences between model organisms and humans, and from failures of experimental paradigms. Not considering these two issues, however, a number of other factors may complicate in vivo use of therapeutic agents. Poor solubility in aqueous media, a particular concern with hydrophobic agents, presents one of the most common problems encountered in the delivery of bioactive agents. Liposome and micelle-based delivery systems (3) help ameliorate this problem by dissolving lipid soluble agents in their hydrophobic core while maintaining solubility in plasma and extracellular fluid as a function of their hydrophilic exterior. Many watersoluble agents, on the other hand, undergo rapid breakdown, because of environmental factors such as ionic strength, $\mathrm{pH}$, or inactivation by enzymes present in the organism. In this case, a delivery system can protect an agent by physically sequestering and isolating it from the unfavorable environment, or preventing enzyme access. Examples of delivery systems used to achieve this include micro- and nanoparticles, which encapsulate the labile drug $(4,5)$. Similarly, when dealing with an agent that is toxic and causes local tissue destruction on administration, such as doxorubicin (6), delivery systems can protect the organism from the drug by regulating its release rate and ensuring that it is released primarily upon reaching its desired site of action. Ways of achieving this include the use of micro- and nanoparticles, as well as implantable hydrogels and polymer matrix delivery systems $(7,8)$. In addition to local toxicity, an agent can also exhibit a high volume of distribution, due to plasma protein binding, adipose tissue sequestration, or high hydrophilicity. Delivery systems described above can also serve to decrease the apparent volume of distribution, thus lowering the doses needed and preventing the accumulation of an agent in normal tissues where it may be toxic. Poor pharmacokinetic profile of an agent also affects the dosage and the administration profile that

Abbreviations: ECM, extracellular matrix; PEG, polyethylene glycol; PLGA, poly(lactic-co-glycolic acid); rhEGF, recombinant human epidermal growth factor; rhEPO, recombinant human erythropoietin; rhVEGF, recombinant human vascular endothelial growth factor 
are required to achieve needed concentrations in plasma. For drugs that are rapidly cleared by the kidney or inactivated by the liver, using a micro- or nanoparticulate delivery system, or a locally targeted reservoir can significantly lower clearance and ameliorate the need for high doses or prolonged infusion times. Conversely, pharmacodynamics of a bioactive agent are, by definition, not changed through the use of drugdelivery techniques in the strict sense of drug-receptor interaction dynamics. However, controlled drug delivery still plays an important role in situations where an agent has an unfavorable pharmacodynamic profile. For example, higher local concentrations of an agent can be created through selective targeting or depot delivery, making it possible to achieve desired biologic effects even in the face of low agent-target affinity. Finally, an issue that has recently received significant attention concerns the lack of selectivity of bioactive agents for their desired targets. It arises when molecular mechanisms targeted by an agent are not unique to diseased tissues or cells, and the solubility and the pharmacokinetic profile of the agent in question result in indiscriminant delivery to healthy tissues. This is of particular concern in cancer and immune chemotherapeutics, where such agents tend to produce significant side effects, thus limiting the acceptable dose range and duration of treatment. Bioengineered-delivery systems, which will be described in more detail later, are being developed to specifically target desired tissues or cell types, in a process known as active targeting.

\section{PROTEINS ARE POWERFUL THERAPEUTICS}

Proteins are fundamental participants in virtually all biologic processes. As such, they represent potentially powerful therapeutic agents. Biologically active proteins with potential for therapeutic delivery include growth factors, hormones, antibodies, and antigens (9).

Tissue engineering will likely assume a unique place in the forthcoming wave of new personalized therapies. Although bioactive agents can reverse or correct certain types of pathologies, or trigger tissue self-repair in certain cases, there are a large number of patients for whom the only answer lies in the ability to replace tissues or whole organs irreparably damaged by injury or disease. For these patients, traditional approaches have included some combination of autologous grafting, xenoand allotransplantation. However, these therapies are problematic due to low availability of replacement tissues, their limited durability, and a requirement for life-long immunosupression in case of allotransplantation.

It is increasingly well understood that new tissue growth, both in vivo during development and in vitro in tissue engineering applications is a complex process requiring an exact spatial and temporal interaction between cells, threedimensional extracellular matrix (ECM), mechanical forces, and numerous signaling proteins (such as mitogens, growth, transcription, and apoptotic factors). Controlled proteindelivery systems represent a crucial method for achieving spatial and temporal concentration profiles of signaling proteins in the extracellular niche of newly developing tissues.
Given these challenges, what are the specific techniques that biomedical engineering currently offers to optimize and customize protein delivery? What obstacles remain, and what are the emerging protein-delivery technologies that will help us address them?

\section{IMPLANTABLE SCAFFOLDS CAN SERVE AS PROTEIN-DELIVERY SYSTEMS}

Macroscopic matrices manufactured from a variety of solid biocompatible materials have played an important role as both depots for drug delivery (10) and as scaffolds in tissue engineering (11). When produced from biodegradable polymers, they are broken down over time, either through hydrolysis or enzymatic action. If loaded with proteins or other bioactive agents, such matrices can release them as they degrade at a known rate. Because of these properties, and the fact that the rates of scaffold degradation can be modified by chemical processing and the introduction of copolymers (12), they have been harnessed for local delivery of numerous agents [for review, see (13)]. Materials that have been established and characterized for use in solid scaffold protein-delivery methods include primarily poly(L- or D,L-lactic acid) (PLLA or PDLA) and its various copolymers with poly(glycolic acid), i.e., poly(lactic-co-glycolic acid) (PLGA). Other polymers, such as poly(epsilon-caprolactone) have also recently been used to construct microporous matrices used as drug-delivery devices (14). Other polymers or factors, such as poly(ethylene glycol) (PEG) (15) and heparin (16) have been used in conjunction with these materials to solve the problems of cell adhesion, coagulation, and nonspecific adsorption of other proteins onto the implanted matrix.

The most straightforward method for introducing proteins into a matrix for delivery is by directly including them into the polymer architecture during the manufacturing process. However, problems often occur when the processing of the polymer matrix requires steps that can compromise the protein. For example, certain polymer matrices rely on water-soluble substances to create pores of a desired size during their production (17). These porogens are then dissolved by an aqueous solvent to reveal the pores in the matrix. However, this step can also elute water-soluble proteins from the scaffold. Similarly, strong ionic solvents or high-temperature processing can denature the proteins. To circumvent this issue, several approaches have been developed. Mooney and coworkers (18) have used highly pressurized carbon dioxide as a solvent, followed by a rapid decrease in pressure, which lead to bubble formation and the formation of pores within the scaffold. The resulting decrease in salt porogens that were required meant that the loaded protein was compromised to a much lesser extent. Another approach involves freeze-drying an emulsion of PLGA polymer solution in methylene chloride and an aqueous phase containing the protein of choice (19). Rapid sublimation of solvents results in a porous PLGA matrix with the associated protein. Another way to introduce porosity is to use porogens that can be removed by moderate heat, such as solid lipids and hydrocarbons, making the use of a water solvent unnecessary (20). In tissue-engineering applications, 
electrospinning is a commonly used method of producing polymeric scaffolds: it is a process that employs a strong electric field to produce fibers with nanoscale diameters. Briefly, a polymer solution is delivered into an electric field at a known rate, causing the resultant polymer jet to be attracted to a grounded collector. As the solvent rapidly evaporates, solid fibers are deposited on the collector in the form of nonwoven fabric. Electrospun scaffolds can be engineered to serve as protein-delivery systems by introducing a protein into the polymer solution that is being delivered into the electric field (21), or by designing a coaxial spinneret which makes it possible to spray a protein solution into the electric field in parallel with the polymer (22). The latter approach results in hollow fibers that contain the protein in their core.

Instead of direct incorporation of the protein into the scaffold itself, premade matrices can sometimes be surface-coated with protein solution. Notably, however, this approach is inefficient due to the small amounts of protein that can be attached in this manner, and their unpredictable release properties. Some attempts have been made to advance surface coating techniques, including the introduction of an additional polymer layer on top of the protein layer (23). Another method, known as the layer-by-layer technique, relies on electrostatic interactions between alternating layers of positively and negatively charged polyelectrolytes and proteins, which are used to coat the surface of a polymer (24). Under aqueous conditions encountered in a cellular environment, the electrostatic interactions are disrupted, leading to the release of the protein from the polymer surface.

A strategy conceptually distinct from direct inclusion of proteins into the matrix architecture is the incorporation of a separate protein release system into the structural scaffold (Fig. 1C). Micro- and nanoparticle-based delivery vehicles lend themselves particularly well to this approach. Using the techniques that will be described in the following section, proteins are first encapsulated into particles, whereas the scaffolds are produced in a separate process. An advantage of this approach is that protein is never exposed to the harsh conditions sometimes used in the preparation of scaffolds. However, the additional problem of attaching the protein-

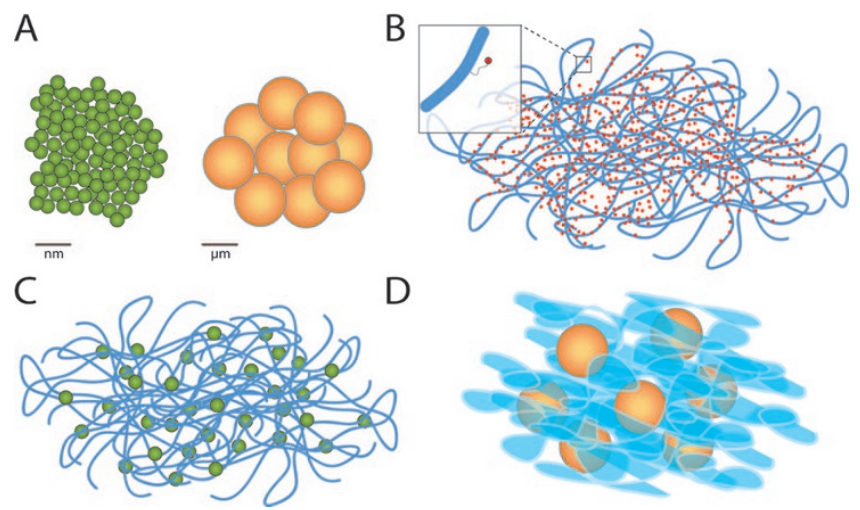

Figure 1. Schematic diagrams of several common methods for controlled delivery of proteins. (A) Nano- (green) and microparticles (orange). (B) Scaffolds with proteins chemically tethered to the surface of the polymer. $(C)$ Protein-loaded nanoparticles incorporated into a polymeric scaffold. $(D)$ Microparticles encapsulating the protein added to a hydrogel. loaded nanoparticles to the polymer matrix is created. The most commonly used techniques for accomplishing this task involve the chemical cross-linking of the matrix polymer (24), use of inorganic cements (25) or the application of solvent evaporation techniques (26). The ultimate result of these manipulations is that the protein-carrying microparticles are physically immobilized within the fibers of the scaffold. In addition to these approaches that rely on physical attachments, novel techniques involving surface modification of nanoparticles are currently being pursued as means of providing mechanisms for chemical linkage. In one recent study, biotin-(PEG)-amine was attached to the surface of PLGA nanoparticles, introducing the potential to harness the biotin-avidin interactions to attach protein-loaded nanoparticles to other substrates (27).

Finally, proteins can be chemically tethered to the surface of the polymer (Fig. 1B). Depending on the specific surface chemistries of polymers, this can be achieved by the introduction of plasma- and radiation-induced radical side chains into the polymer (28), hydroxyl group modification (29), custom side-chain polymer synthesis (30), aforementioned biotin functionalization (27), and the use of PEG-poly(propylene glycol) block copolymers as means of immobilizing large proteins (31). A recent development concerns the development of polymers that have amine- and thiol-reactive chemistries on their surfaces (32), and can therefore be used to bind several different proteins from solution-a property potentially useful for cell patterning in tissue engineering. Surface tethering is not useful for proteins that need to be soluble or have to reach targets inside the cell to be active. Development of strategies to include cleavable constructs is an active area of investigation. As an example, proteins such as epidermal growth factor (33), insulin (34), and nerve growth factor (35) have successfully been attached to surfaces although retaining their biologic activity.

\section{HYDROGELS ARE USED AS PROTEIN DELIVERY SYSTEMS}

Hydrogels differ from the solid scaffolds described in the previous section in one important aspect: they are threedimensional matrices built of hydrophilic polymers, and have very high water content (upwards of 50\%, rising to $90 \%$ in some highly swollen systems) (8). High water content imparts a unique property to hydrogels, which, while macroscopically solids, behave like aqueous solutions on a microscopic scale (36). As a result, the diffusion of molecular species, including water-soluble proteins, within a hydrogel is only limited by their size with respect to the space between individual crosslinked polymer elements (37). Hydrogels have been created from a variety of polymers including collagen, gelatin, fibrin, hyaluronic acid, alginate, chitosan, and dextran (8). Notably, these polymeric proteins and polysaccharides are (or resemble) constituents of the extracellular matrix. Construction of ECM-like materials is common in tissue-engineering applications, both due to their mechanical properties and the fact that they provide important mimicry of the natural extracellular environment (Fig. 2). In addition to natural polymers, hydrogels made from synthetic polymers have also been investi- 


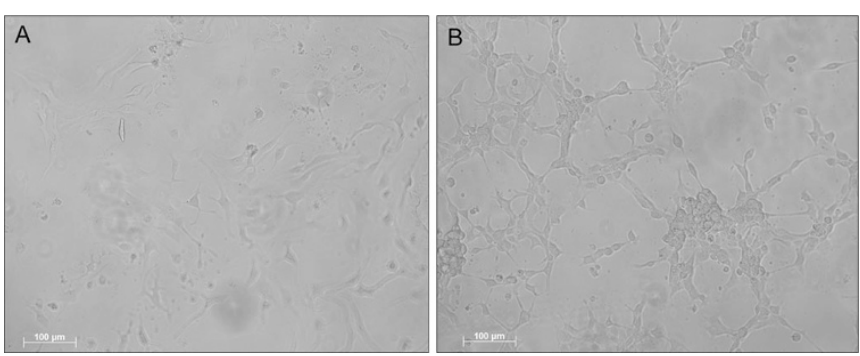

Figure 2. Brightfield micrographs of poly(ethylene glycol)/poly(L-lysine) hydrogels seeded with brain endothelial cells. The hydrogels contained no growth factor in $(A)$ and were loaded with VEGF in $(B)$. The image was kindly provided by Rauch and Lavik, Yale University.

gated, including those based on poly(ethylene oxide), poly(acrylic acid), and poly(vinyl alcohol) (8). Given their biocompatibility, which is a consequence of high water content and the nontoxic polymers used in their production, as well as their consequent importance in tissue engineering, it is not surprising that hydrogels are also widely used as proteindelivery devices (37).

Because of the high water content, it is often difficult to control the rate of release of agents from hydrogels. Individual polymer chains are cross-linked in hydrogels in two principal ways. They can be physically cross-linked, analogous to the entanglement of fibers, or they can be linked through chemical bonds between the polymer units. Physically cross-linked hydrogels tend to break down by simple dissolution, whereas chemically linked ones are dependent on hydrolysis or enzymatic action for degradation (12). Because the rate of protein release from hydrogels is dependent on both the diffusion through the matrix and the rate of hydrogel degradation, it can be controlled by varying the density and nature of cross-links between the polymer chains of the hydrogel (12). A variety of manipulations have been used to modify the degree of crosslinking and control release rates. These techniques have been reviewed elsewhere (8), with a few examples including UV light, thermal processing, glutaraldehyde cross-linking, and Michael-type additions.

Proteins can be incorporated into hydrogels in several ways. When proteins are directly incorporated into the hydrogels, they interact with the polymer units and their release profile is dependent on the strength of these interactions. There are soluble factors that are known to interact with particular types of polymers, an important consideration in the design of hydrogel-based protein release systems. A well-known example is the vascular endothelial growth factor (VEGF) and its synergistic interaction with alginate (38). Most of the time this direct approach results in an initial burst release, followed by some low level prolonged release over time. As described previously, release can sometimes be modulated by cross-link modification, but care must be taken because the procedures used to enhance cross-linking may be detrimental to the protein itself. Using this approach, epidermal growth factor (39), human growth hormone (40), ciliary neurotrophic factor (41), brain-derived neurotrophic factor (42), and neurotrophin-3 (43) have been delivered in various models.

When more robust release profiles are required, a separate protein-delivery system, such as protein-loaded micro- or nanoparticles, may be added to the hydrogel (Fig. 1D). This approach significantly changes the release profile of the system as a whole, as it makes it dependent on both the degradation and release properties of a separate polymer carrier, and the subsequent interaction with the hydrogel matrix. Consequently, finer control over protein release is theoretically possible, as cross-linking of the hydrogels and the production parameters of the particles can be controlled independently. For example, in cartilage-engineering applications, one group incorporated transforming growth factor $\beta 1$ in gelatin microparticles into an oligo(poly(ethylene glycol) fumarate) gel (44), while investigators who delivered it using PLGA microparticles in a PEG-based hydrogel (45) obtained different release profiles. Other examples of this approach include use in bone regeneration, where insulin-like growth factor I encapsulated in PLGA microparticles was placed into an alginate-tricalciumphosphate hydrogels (46) and delivery of VEGF from alginate microparticles incorporated into collagen/fibronectin hydrogels for new vessel formation (data not published).

Direct attachment of proteins to the polymer chains of hydrogels has also been achieved. For example, using covalent linking, transforming growth factor $\beta 1$ was attached to PEG hydrogels, leading to increased mechanical strength of engineered smooth muscle (47).

\section{MICRO- AND NANOPARTICLES PLAY AN IMPORTANT ROLE IN PROTEIN DELIVERY}

Proteins can be encapsulated into microscopic spherical constructs that act as protein carriers and delivery systems (Fig. $1 A)$. Micro- and nanoparticles are produced from a number of nondegradable and degradable polymers, of both synthetic and natural origin. Particles that are $1-100 \mu \mathrm{m}$ in diameter are generally considered to be microparticles, whereas particles $1-100 \mathrm{~nm}$ in diameter are nanoparticles (12). Size is important. In addition to altering the rate of protein release, due to different surface-to-volume ratios, smaller particle size is especially desirable for applications where intracellular uptake [for review, see (48)] or the crossing of the blood-brain barrier (49) is desired. For example, it has been shown that $100 \mathrm{~nm}$ particles are taken up by cells 2.5 times more readily than microparticles $1 \mu \mathrm{m}$ in diameter (50).

Some authors differentiate nanocapsules, in which a distinct polymer membrane surrounds a vesicular space that contains the agent, from nanospheres, which consist of a homogenous spherical matrix with the agent dispersed throughout its volume (5). Because nondegradable materials carry risks arising from their toxicity and potential persistence in the body, micro- and nanoparticles are generally made from biodegradable polymers (51). Polyesters are most commonly used, such as poly(L-lactic acid), poly(glycolic acid), poly(epsiloncaprolactone), and especially PLGA copolymers, as lactic and glycolic acid are easily metabolized in the citric acid cycle (48). Several preparations using PLGA microparticles are currently FDA approved and used clinically (52). Natural polymers for particle preparation have included both proteins (e.g., collagen, albumin, gelatin) and polysaccharides (e.g., alginate, chitosan, dextran, hyaluronic acid) (4). 
Proteins can be encapsulated using a number of techniques. The choice of a particular technique depends on properties of the polymers being used, the characteristics of the protein being delivered, and the desired release profile. Production methods have been addressed by other reviews in more detail $(4,5)$, but the most commonly used ones are reviewed here. Double emulsion method uses an aqueous buffer containing the protein to create a water/oil emulsion with the polymer dissolved in an organic solvent, typically dichloromethane. After the emulsion is achieved by homogenization or sonication, it is transferred into a water-based medium, usually containing poly(vinyl alcohol) as a stabilizer, where a double water/oil/water emulsion is again created. As the organic solvent is removed by extraction, vacuum, or heat, particles containing the protein are created. The main advantages of this method are the use of a mild aqueous solvent; reasonable encapsulation efficiencies are often, but not always, obtained. The size of the particles can be influenced by changing the conditions, such as the speed of homogenization. In spray drying, protein in a solid form (i.e., lyophilized) must be added directly into a volatile organic solution of the polymer, where it is distributed using a homogenizer. Using heated air, the mix of the polymer and the protein is atomized, whereby microspheres (typically $1-100 \mu \mathrm{m}$ in diameter) are formed due to rapid solvent evaporation. They are usually isolated in a cyclone separator, making this technique more challenging and expensive. Finally, phase separation is sometimes used. In this method, silicon oil is used to reduce the solubility of the polymer in dichloromethane solution that also contains dispersed lyopholized protein. This causes encapsulation into particles, which are then hardened and washed with heptane.

Proteins are released from micro- and nanoparticles due to a combination of diffusion through the polymer matrix and the degradation and dissolution of the particle itself (52). There is also usually an initial release (or "burst") of the protein adsorbed on the surface of the particle. The degradation profile and crosslink density of polymer chains that determines diffusion both depend on attributes such as individual polymer molecular weights, copolymer ratios, and their resulting glass transition temperature, crystallinity, and hydrophilicity (4). It therefore follows that drug-release profiles can be controlled through modification of these properties and the manufacturing process.

Micro- and nanoparticles have been used to deliver a wide array of soluble proteins for different applications in various systems, both in vitro and in vivo (Fig. 3). Some of the more important applications have included delivery of encapsulated antigens for vaccination, enzymes, and hormones as potential therapeutic agents, as well as growth factors and mitogens in tissue-engineering constructs. As examples, inactivated Group B Streptococcus antigen with a $\mathrm{CpG}$ adjuvant delivered by PLGA microcapsules has been shown to induce a more robust antibody response than a nonencapsulated antigen (53). Notably, however, PLGA nanoparticles themselves have been found to have adjuvant properties, for example, when delivering staphylococcal enterotoxin B toxoid (54). Some other antigens shown to induce immunity when encapsulated in PLGA microparticles have included the tetanus (55) and diphtheria (56) toxoids.

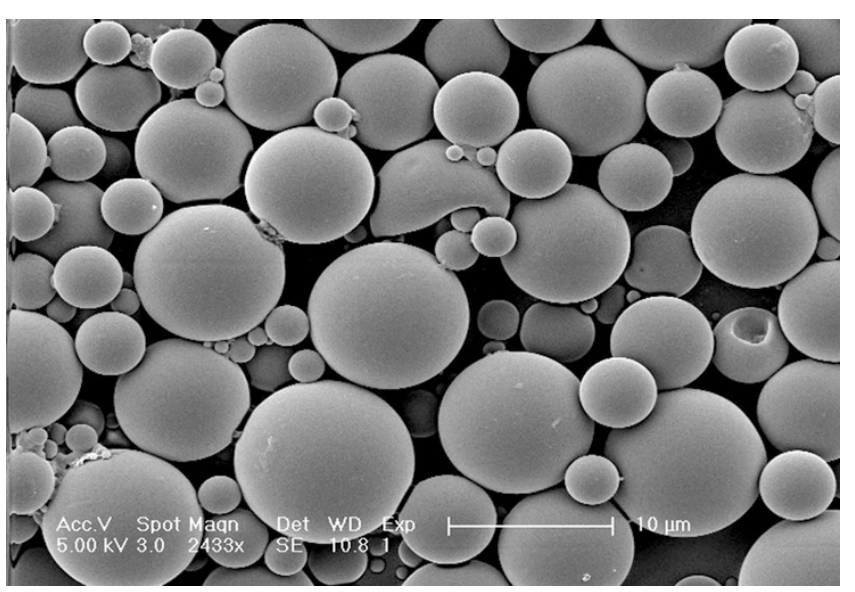

Figure 3. Electron micrograph showing PLGA microparticles loaded with IL-2. The image was kindly provided by Steenblock and Fahmy, Yale University.

Attempts to improve native tissue regeneration and bioengineering of novel tissues in the laboratory have relied heavily on delivery of encapsulated growth factors. For example, basic fibroblast growth factor encapsulated in gelatin microspheres induced the formation of collateral circulation in a rabbit ischemia model (57), whereas recombinant human vascular endothelial growth factor (rhVEGF) promoted local angiogenesis when delivered using PLGA microspheres (58). Other growth factors, including insulin-like growth factor I (59), recombinant human epithermal growth factor (rhEGF) (60) and bone morphogenetic protein-2 (61) are being also investigated.

As an example of microparticle-mediated protein delivery for human therapeutic applications, Breuer and coworkers have recently developed PLGA microspheres that release parathyroid hormone for the treatment of hypoparathyroidism (62). Similarly, it has been shown that delivery of pigment epithelium-derived factor from PLGA microparticles protects retinal ganglion cells from transient ischemic injury (63). In addition, insulin (64), recombinant human erythropoietin (rhEPO) (65), prolidase (66) and interferon- $\alpha$ (67) have also been delivered through micro- or nanoencapsulation for therapeutic purposes.

\section{PROTEIN DELIVERY METHODS ARE BECOMING MORE SOPHISTICATED}

One challenge faced by tissue engineers arises from the complex cellular environment that is required for proper growth and functioning of tissues. It is now well understood that developmental signals consist of numerous factors orchestrated in a specific spatial and temporal sequence. As such, controlled protein-delivery systems provide a way to deliver multiple soluble proteins at different rates and, potentially, in a different spatial orientation to mimic the native developmental environment as closely as possible. Mooney and coworkers have shown an advantage for guiding a formation of a mature vascular network when two distinct mitogens, VEGF and platelet-derived growth factor, are delivered at different rates from a single structural polymer scaffold (18), by using a combination of direct inclusion of VEGF into the 
PLGA matrix and the incorporation of platelet-derived growth factor encapsulated in PLGA microparticles. The same group has since demonstrated similar advances in muscle (68) and bone (69) regeneration.

One of the most important advances in the field of controlled drug delivery is micro- and nanoparticle surface modification. Surface modification can turn a protein-carrying particle into a customized delivery package, with enhanced ability to interact with biologic tissues or cells. Some of the surface modifications being tested include the attachment of targeting antibodies, cellular uptake ligands, and moieties that improve biocompatibility or diffusion through tissues. Novel methods are being developed for the attachment of ligands to the particle surface; the reader is pointed to several extensive reviews for more information $(48,70,71)$.

There are several surface modification approaches that deserve special mention. A significant problem in particulate drug-delivery systems concerns the interactions of the polymeric carriers with the proteins and other constituents of the extracellular environment, leading both to decreased biocompatibility and impaired diffusion. This unwanted interaction has serious implications with respect to the efficiency and spatial distribution of delivered drugs. One of the most powerful surface modification methods for minimizing these interactions to have emerged is addition of PEG, also called PEGylation. PEGylation has been shown to significantly increase the circulation time for proteins in the blood (72) and diffusion constants of proteins in tissues (73). PEG is a highly hydrophilic flexible polymer that effectively ensures hydration and water shielding of polymeric particles, a method that has been increasingly used in protein delivery [for review see (74)]. One of the most promising recent developments in the field has centered on the concept of targeted delivery of bioactive agents to diseased tissues, known widely as "the magic bullet" (70). With the problems arising from nonspecific delivery of drugs and proteins into tissues, which include large volumes of distribution and toxicity (described earlier in this article), much attention has been paid to finding ways to deliver agents of choice only to tissues where effects are desired. A typical example includes cancer chemotherapy. Tumors tend to display enhanced permeability due to the vascular and ECM changes, which leads to some level of accumulation and retention of particulate delivery vehicles. This is known as the enhanced permeability and retention effect, and is an example of passive targeting (75). However, to achieve efficient and reproducible targeting of proteins and chemotherapeutics, a more sophisticated method is often needed. A major way for achieving this "active targeting" has included surface modification of nanoparticles with tissue-specific ligands (70) (Fig. 4). What about monitoring the distribution of agents delivered using particulate delivery systems? Recent developments have included the attachment of contrast agents (e.g., gadolinium diethylene triamine pentaacetic acid lipids) to the surface of PLGA particles rendering them detectable by magnetic resonance imaging [for review see (76)].

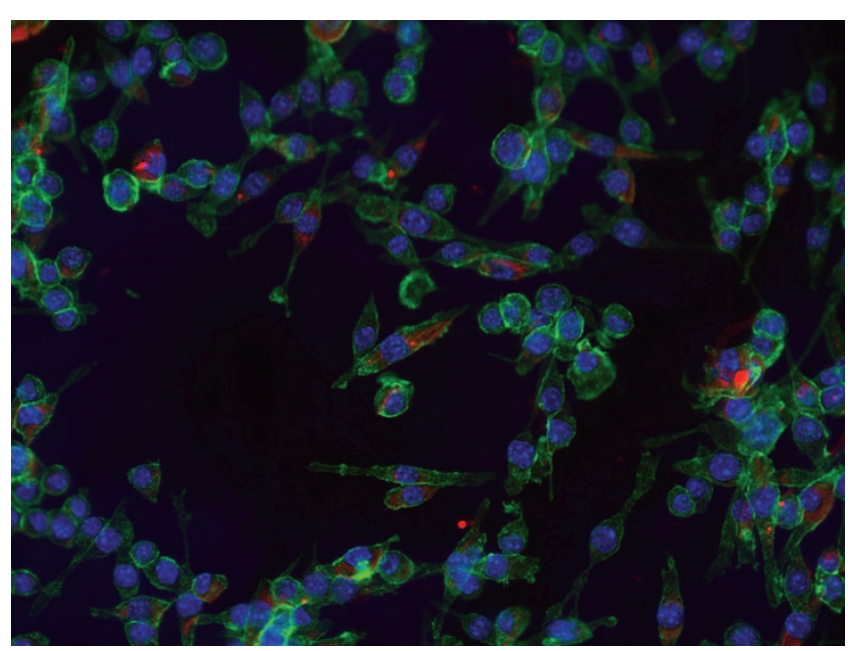

Figure 4. DC2.4 cells stained with FITC- phalloidin (green) and DAPI (blue) shown interacting with rhodamine-loaded PLGA nanoparticles (red) that were surface modified with a ligand specific to dendritic cells. The stronger red signal represents rhodamine nanoparticles outside the cells, whereas the diffuse red signal originates from nanoparticles taken up by the cells. The image was kindly provided by Demento and Fahmy, Yale University.

\section{BIOENGINEERED SYSTEMS FOR CONTROLLED DELIVERY REPRESENT IMMENSELY IMPORTANT TOOLS FOR THERAPEUTIC DELIVERY OF PROTEINS}

The recent advances in the field have improved our ability to deliver proteins in efficient and specific ways. Although many challenges remain, this rise of sophistication has already had significant impacts in the development of therapeutics and bioengineered tissues for treating human injury and diseaseand will bring many more.

Acknowledgments. We are indebted to Stacey Demento, Dr. Tarek Fahmy, Dr. Erin Lavik, Millicent Ford Rauch, and Erin Steenblock for helpful discussions and for providing images.

\section{REFERENCES}

1. Szuromi P, Vinson V, Marshall E 2004 Rethinking drug discovery. Science 303:1795

2. Allen TM, Cullis PR 2004 Drug delivery systems: entering the mainstream. Science 303:1818-1822

3. Samad A, Sultana Y, Aqil M 2007 Liposomal drug delivery systems: an update review. Curr Drug Deliv 4:297-305

4. Sinha VR, Trehan A 2003 Biodegradable microspheres for protein delivery. J Control Release 90:261-280

5. Soppimath KS, Aminabhavi TM, Kulkarni AR, Rudzinski WE 2001 Biodegradable polymeric nanoparticles as drug delivery devices. J Control Release 70:1-20

6. Von Hoff DD, Layard MW, Basa P, Davis HL, Von Hoff AL, Rozencweig M, Muggia FM 1979 Risk factors for doxorubicin-induced congestive heart failure. Ann Intern Med 91:710-717

7. Sershen S, West J 2002 Implantable, polymeric systems for modulated drug delivery. Adv Drug Deliv Rev 54:1225-1235

8. Lee KY, Yuk SH 2007 Polymeric protein delivery systems. Prog Polym Sci 32:669-697

9. Saltzman WM, Olbricht WL 2002 Building drug delivery into tissue engineering design. Nat Rev Drug Discov 1:177-186

10. Krewson CE, Dause R, Mak M, Saltzman WM 1996 Stabilization of nerve growth factor in controlled release polymers and in tissue. J Biomater Sci Polym Ed 8:103-117

11. Borenstein JT, Weinberg EJ, Orrick BK, Sundback C, Kaazempur-Mofrad MR, Vacanti JP 2007 Microfabrication of three-dimensional engineered scaffolds. Tissue Eng 13:1837-1844

12. Baldwin SP, Mark Saltzman W 1998 Materials for protein delivery in tissue engineering. Adv Drug Deliv Rev 33:71-86

13. Tessmar JK, Gopferich AM 2007 Matrices and scaffolds for protein delivery in tissue engineering. Adv Drug Deliv Rev 59:274-291 
14. Chang HI, Williamson MR, Perrie Y, Coombes AG 2005 Precipitation casting of drug-loaded microporous PCL matrices: incorporation of progesterone by codissolution. J Control Release 106:263-272

15. Tessmar JK, Gopferich AM 2007 Customized PEG-derived copolymers for tissueengineering applications. Macromol Biosci 7:23-39

16. Wang XH, Li DP, Wang WJ, Feng QL, Cui FZ, Xu YX, Song XH 2003 Covalent immobilization of chitosan and heparin on PLGA surface. Int J Biol Macromol 33:95-100

17. Tessmar JK, Holland TA, Mikos AG 2005 Salt leaching for polymer scaffolds: laboratory-scale manufacture of cell carriers. In: Ma PX, Elisseeff JH (eds) Scaffolding in Tissue Engineering. Taylor \& Francis (CRC Press), Boca Raton, pp 111-124

18. Richardson TP, Peters MC, Ennett AB, Mooney DJ 2001 Polymeric system for dual growth factor delivery. Nat Biotechnol 19:1029-1034

19. Whang K, Goldstick TK, Healy KE 2000 A biodegradable polymer scaffold for delivery of osteotropic factors. Biomaterials 21:2545-2551

20. Shastri VP, Martin I, Langer R 2000 Macroporous polymer foams by hydrocarbon templating. Proc Natl Acad Sci USA 97:1970-1975

21. Li C, Vepari C, Jin H-J, Kim HJ, Kaplan DL 2006 Electrospun silk-BMP-2 scaffolds for bone tissue engineering. Biomaterials 27:3115-3124

22. Zhang YZ, Wang X, Feng Y, Li J, Lim CT, Ramakrishna S 2006 Coaxial electrospinning of (fluorescein isothiocyanate-conjugated bovine serum albumin)encapsulated poly(-caprolactone) nanofibers for sustained release. Biomacromolecules 7:1049-1057

23. Sohier J, Haan RE, de Groot K, Bezemer JM 2003 A novel method to obtain protein release from porous polymer scaffolds: emulsion coating. J Control Release 87:57-68

24. Hedberg EL, Tang A, Crowther RS, Carney DH, Mikos AG 2002 Controlled release of an osteogenic peptide from injectable biodegradable polymeric composites. J Control Release 84:137-150

25. Ruhe PQ, Boerman OC, Russel FG, Spauwen PH, Mikos AG, Jansen JA 2005 Controlled release of rhBMP-2 loaded poly(D,L-lactic-co-glycolic acid)/calcium phosphate cement composites in vivo. J Control Release 106:162-171

26. Meese TM, Hu Y, Nowak RW, Marra KG 2002 Surface studies of coated polymer microspheres and protein release from tissue-engineered scaffolds. J Biomater Sci Polym Ed 13:141-151

27. Weiss B, Schneider M, Muys L, Taetz S, Neumann D, Schaefer UF, Lehr CM 2007 Coupling of biotin-(poly(ethylene glycol))amine to poly(D,L-lactide-co-glycolide) nanoparticles for versatile surface modification. Bioconjug Chem 18:1087-1094

28. Cima LG 1994 Polymer substrates for controlled biological interactions. J Cell Biochem 56:155-161

29. Mikulec LJ, Puleo DA 1996 Use of p-nitrophenyl chloroformate chemistry to immobilize protein on orthopedic biomaterials. J Biomed Mater Res 32:203-208

30. Shakesheff K, Cannizzaro S, Langer R 1998 Creating biomimetic microenvironments with synthetic polymer-peptide hybrid molecules. J Biomater Sci Polym Ed 9:507-518

31. Biran R, Webb K, Noble MD, Tresco PA 2001 Surfactant-immobilized fibronectin enhances bioactivity and regulates sensory neurite outgrowth. J Biomed Mater Res 55:1-12

32. Tessmar JK, Mikos AG, Gopferich A 2002 Amine-reactive biodegradable diblock copolymers. Biomacromolecules 3:194-200

33. Kuhl PR, Griffith-Cima LG 1996 Tethered epidermal growth factor as a paradigm for growth factor-induced stimulation from the solid phase. Nat Med 2:1022-1027

34. Kim EJ, Kang IK, Jang MK, Park YB 1998 Preparation of insulin-immobilized polyurethanes and their interaction with human fibroblasts. Biomaterials 19:239-249

35. Frazier WA, Boyd LF, Bradshaw RA 1973 Interaction of nerve growth factor with surface membranes: biological competence of insolubilized nerve growth factor. Proc Natl Acad Sci USA 70:2931-2935

36. Prokop A, Kozlov E, Carlesso G, Davidson J 2002 Hydrogel-based colloidal polymeric system for protein and drug delivery: physical and chemical characterization, permeability control and applications. In: Arora M (ed) Filled Elastomers Drug Delivery Systems. Springer Berlin, Heidelberg, pp 119-173

37. Lee KY, Mooney DJ 2001 Hydrogels for tissue engineering. Chem Rev 101:1869-1879

38. Peters MC, Isenberg BC, Rowley JA, Mooney DJ 1998 Release from alginate enhances the biological activity of vascular endothelial growth factor. J Biomater Sci Polym Ed 9:1267-1278

39. Hori K, Sotozono C, Hamuro J, Yamasaki K, Kimura Y, Ozeki M, Tabata Y, Kinoshita S 2007 Controlled-release of epidermal growth factor from cationized gelatin hydrogel enhances corneal epithelial wound healing. J Control Release 118:169-176

40. Tae G, Kornfield JA, Hubbell JA 2005 Sustained release of human growth hormone from in situ forming hydrogels using self-assembly of fluoroalkyl-ended poly(ethylene glycol). Biomaterials 26:5259-5266

41. Burdick JA, Ward M, Liang E, Young MJ, Langer R 2006 Stimulation of neurite outgrowth by neurotrophins delivered from degradable hydrogels. Biomaterials 27:452-459

42. Bakshi A, Fisher O, Dagci T, Himes BT, Fischer I, Lowman A 2004 Mechanically engineered hydrogel scaffolds for axonal growth and angiogenesis after transplantation in spinal cord injury. J Neurosurg Spine 1:322-329

43. Piantino J, Burdick JA, Goldberg D, Langer R, Benowitz LI 2006 An injectable, biodegradable hydrogel for trophic factor delivery enhances axonal rewiring and improves performance after spinal cord injury. Exp Neurol 201:359-367

44. Park H, Temenoff JS, Tabata Y, Caplan AI, Mikos AG 2007 Injectable biodegradable hydrogel composites for rabbit marrow mesenchymal stem cell and growth factor delivery for cartilage tissue engineering. Biomaterials 28:3217-3227

45. DeFail AJ, Chu CR, Izzo N, Marra KG 2006 Controlled release of bioactive TGF-[beta]1 from microspheres embedded within biodegradable hydrogels. Biomaterials 27:1579-1585

46. Luginbuehl V, Wenk E, Koch A, Gander B, Merkle HP, Meinel L 2005 Insulin-like growth factor I-releasing alginate-tricalciumphosphate composites for bone regeneration. Pharm Res 22:940-950
47. Mann BK, Schmedlen RH, West JL 2001 Tethered-TGF-[beta] increases extracellular matrix production of vascular smooth muscle cells. Biomaterials 22:439-444

48. Panyam J, Labhasetwar V 2003 Biodegradable nanoparticles for drug and gene delivery to cells and tissue. Adv Drug Deliv Rev 55:329-347

49. Kroll RA, Pagel MA, Muldoon LL, Roman-Goldstein S, Fiamengo SA, Neuwelt EA 1998 Improving drug delivery to intracerebral tumor and surrounding brain in a rodent model: a comparison of osmotic versus bradykinin modification of the blood-brain and/or blood-tumor barriers. Neurosurgery 43:879-886

50. Desai MP, Labhasetwar V, Walter E, Levy RJ, Amidon GL 1997 The mechanism of uptake of biodegradable microparticles in Caco-2 cells is size dependent. Pharm Res 14:1568-1573

51. Jalil R, Nixon JR 1990 Biodegradable poly(lactic acid) and poly(lactide-coglycolide) microcapsules: problems associated with preparative techniques and release properties. J Microencapsul 7:297-325

52. Freiberg S, Zhu XX 2004 Polymer microspheres for controlled drug release. Int J Pharm 282:1-18

53. Hunter SK, Andracki ME, Krieg AM 2001 Biodegradable microspheres containing group B Streptococcus vaccine: immune response in mice. Am J Obstet Gynecol 185:1174-1179

54. Desai MP, Hilfinger JM, Amidon GL, Levy RJ, Labhasetwar V 2000 Immune response with biodegradable nanospheres and alum: studies in rabbits using staphylococcal enterotoxin B-toxoid. J Microencapsul 17:215-225

55. Jung T, Koneberg R, Hungerer KD, Kissel T 2002 Tetanus toxoid microspheres consisting of biodegradable poly(lactide-co-glycolide)- and ABA-triblockcopolymers: immune response in mice. Int J Pharm 234:75-90

56. Johansen P, Moon L, Tamber H, Merkle HP, Gander B, Sesardic D 1999 Immunogenicity of single-dose diphtheria vaccines based on PLA/PLGA microspheres in guinea pigs. Vaccine 18:209-215

57. Hosaka A, Koyama H, Kushibiki T, Tabata Y, Nishiyama N, Miyata T, Shigematsu H, Takato T, Nagawa H 2004 Gelatin hydrogel microspheres enable pinpoint delivery of basic fibroblast growth factor for the development of functional collateral vessels. Circulation 110:3322-3328

58. Cleland JL, Duenas ET, Park A, Daugherty A, Kahn J, Kowalski J, Cuthbertson A 2001 Development of poly-(D,L-lactide-co-glycolide) microsphere formulations containing recombinant human vascular endothelial growth factor to promote local angiogenesis. J Control Release 72:13-24

59. Yuksel E, Weinfeld AB, Cleek R, Waugh JM, Jensen J, Boutros S, Shenaq SM, Spira M 2000 De novo adipose tissue generation through long-term, local delivery of insulin and insulin-like growth factor-1 by PLGA/PEG microspheres in an in vivo rat model: a novel concept and capability. Plast Reconstr Surg 105:1721-1729

60. Han K, Lee KD, Gao ZG, Park JS 2001 Preparation and evaluation of poly(L-lactic acid) microspheres containing rhEGF for chronic gastric ulcer healing. J Control Release 75:259-269

61. Isobe M, Yamazaki Y, Mori M, Ishihara K, Nakabayashi N, Amagasa T 1999 The role of recombinant human bone morphogenetic protein-2 in PLGA capsules at an extraskeletal site of the rat. J Biomed Mater Res 45:36-41

62. Fong P, Goyal A, Brennan M, Park J, Moss L, Saltzman WM, Breuer CK 2007 Development of PTH eluting microspheres for the treatment of hypoparathyroidism. J Surg Res 143:195-199

63. Li H, Tran VV, Hu Y, Mark Saltzman W, Barnstable CJ, Tombran-Tink J 2006 A PEDF N-terminal peptide protects the retina from ischemic injury when delivered in PLGA nanospheres. Exp Eye Res 83:824-833

64. Carino GP, Jacob JS, Mathiowitz E 2000 Nanosphere based oral insulin delivery. J Control Release 65:261-269

65. Morlock M, Kissel T, Li YX, Koll H, Winter G 1998 Erythropoietin loaded microspheres prepared from biodegradable LPLG-PEO-LPLG triblock copolymers: protein stabilization and in-vitro release properties. J Control Release 56:105-115

66. Genta I, Perugini P, Pavanetto F, Maculotti K, Modena T, Casado B, Lupi A, Iadarola P, Conti B 2001 Enzyme loaded biodegradable microspheres in vitro ex vivo evaluation. J Control Release 77:287-295

67. Zhou S, Deng X, He S, Li X, Jia W, Wei D, Zhang Z, Ma J 2002 Study on biodegradable microspheres containing recombinant interferon-alpha-2a. J Pharm Pharmacol 54:1287-1292

68. Hill E, Boontheekul T, Mooney DJ 2006 Regulating activation of transplanted cells controls tissue regeneration. Proc Natl Acad Sci USA 103:2494-2499

69. Oest ME, Dupont KM, Kong H-J, Mooney DJ, Guldberg RE 2007 Quantitative assessment of scaffold and growth factor-mediated repair of critically sized bone defects. J Orthop Res 25:941-950

70. Fahmy TM, Fong PM, Goyal A, Saltzman WM 2005 Targeted for drug delivery. Mater Today 8:18-26

71. Lu Y, Yang J, Sega E 2006 Issues related to targeted delivery of proteins and peptides. AAPS J 8:E466-E478

72. Werle M, Bernkop-Schnurch A 2006 Strategies to improve plasma half life time of peptide and protein drugs. Amino Acids 30:351-367

73. Stroh M, Zipfel WR, Williams RM, Ma SC, Webb WW, Saltzman WM 2004 Multiphoton microscopy guides neurotrophin modification with poly(ethylene glycol) to enhance interstitial diffusion. Nat Mater 3:489-494

74. Otsuka H, Nagasaki Y, Kataoka K 2003 PEGylated nanoparticles for biological and pharmaceutical applications. Adv Drug Deliv Rev 55:403-419

75. Maeda H, Wu J, Sawa T, Matsumura Y, Hori K 2000 Tumor vascular permeability and the EPR effect in macromolecular therapeutics: a review. J Control Release 65:271-284

76. Fahmy TM, Fong PM, Park J, Constable T, Saltzman WM 2007 Nanosystems for simultaneous imaging and drug delivery to T cells. AAPS J 9:E171-E180 